
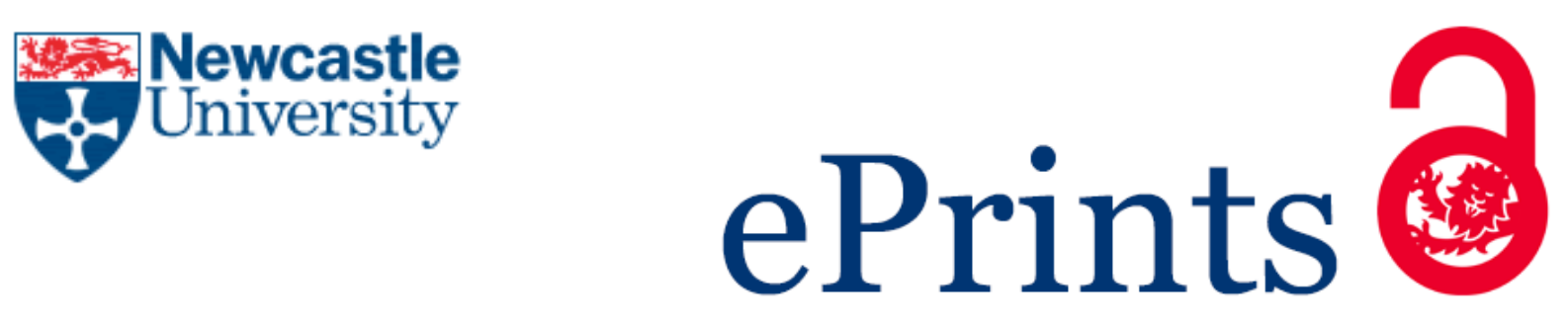
Byers E, Qadrdan M, Leathard A, Alderson D, Hall JW, Amezaga JM, Tran M, Kilsby CG, Chaudry M. (2015)
Cooling water for Britain's future electricity supply.
Proceedings of the ICE - Energy
DOI: $10.1680 /$ ener.14.00028

\title{
Copyright:
}

Published with permission by the ICE under the CC-BY license.

(http://creativecommons.org/licenses/by/4.0/)

Link to published article:

http://dx.doi.org/10.1680/ener.14.00028

Date deposited:

$11 / 06 / 2015$

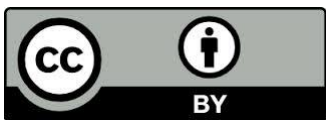

This work is licensed under a Creative Commons Attribution 4.0 International License 


\section{Cooling water for Britain"s future electricity supply}

Edward A. Byers MEng

Postgraduate Researcher in Infrastructure Systems, Newcastle University, Newcastle upon Tyne, UK

Meysam Qadrdan BSc, MSc, PhD

Lecturer in Energy Networks and Systems, Institute of Energy, Cardiff University, Cardiff, UK

\section{Alex Leathard MEng}

Research Associate in Water Resources, School of Civil Engineering \& Geosciences, Newcastle University, Newcastle upon Tyne, UK

David Alderson BSC

Research Assistant in Geolnformatics, School of Civil Engineering

\& Geosciences, Newcastle University, Newcastle upon Tyne, UK

Jim W. Hall PhD, FREng

Professor of Climate and Environmental Risks and Director,

Environmental Change Institute, University of Oxford, Oxford, UK
Jaime M. Amezaga MSc, MSc, PhD

Reader in Environmental Sustainability, School of Civil Engineering

\& Geosciences, Newcastle University, Newcastle upon Tyne, UK

Martino Tran MSc, DPhil

Senior Research Fellow, Environmental Change Institute,

University of Oxford, Oxford, UK

Chris G. Kilsby BSC, CMet

Professor of Hydrology and Climate Change, School of Civil Engineering \& Geosciences, Newcastle University, Newcastle upon Tyne, UK

Modassar Chaudry BSc, MSc, PhD

Research Associate, Institute of Energy, Cardiff University, Cardiff, UK

Trends in the locations and technologies of UK electricity generation plant suggest that demand for cooling water abstractions from rivers will decrease in the coming decades, unless there is widespread uptake of carbon dioxide capture and storage (CCS). CCS may prove to be essential if the UK is to achieve its carbon dioxide and greenhouse gas emission targets. 'Decarbonisation' strategies that rely on CCS are therefore potentially at risk of not having sufficient cooling water in periods of low river flows. In this paper, regional freshwater demands for cooling water are assessed against regional freshwater availability at low flows in a scenario of medium climate change. In the strategy with high CCS, demands for water greatly exceed current and future availability in the north-west (NW) England, Humber, East (E) Midlands and Thames regions. These risks can be mitigated by increasing the penetration of hybrid cooling systems or shifting generating capacity to estuaries or the coast. The former could reduce national water use by up to $35 \%$, whereas applying the latter in the NW England, Humber and E Midlands regions offers nationwide reductions from 30 to $50 \%$.

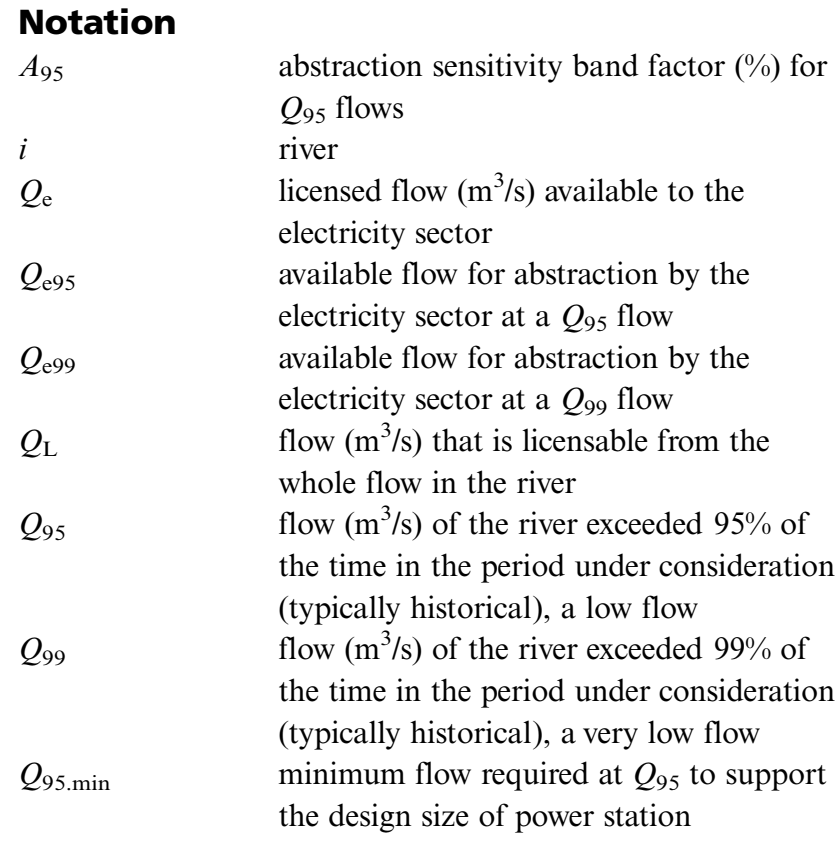

$S_{\mathrm{e}} \quad$ proportion (\%) of the total licensable flow that is available to the electricity sector, determined by the licences held by the sector

\section{Introduction}

Over the last decade, numerous thermoelectric power stations across the world have faced output reductions and shutdown due to either cooling water that was too warm or insufficient in volume. France has had to reduce generation at river-based nuclear plants in 2003 and 2006, while between 2006 and 2012, 26 coal and nuclear power stations in the USA have been similarly affected (Spanger-Siegfried, 2013; UCS, 2011, 2012). Due to concerns over security of electricity supply, in the last few years there has been a number of studies evaluating the use of freshwater for cooling at power stations. Some studies seek to determine whether high temperatures and reducing river flows due to climate change present risks to thermoelectric power production, usually at a river basin scale 
(Cohen et al., 2014; Förster and Lilliestam, 2009; Koch and Vögele, 2009, 2013; Koch et al., 2014; Naughton et al., 2012; Scanlon et al., 2013; Stillwell and Webber, 2013; Stillwell et al., 2011). Others have quantified current and future freshwater demands from different energy pathways, such as for the USA (Macknick et al., 2012b), the UK (Byers et al., 2014; Hall et al., 2015; Tran et al., 2014), China (Pan et al., 2012) or the whole world (Hadian and Madani, 2013).

This paper combines aspects of both approaches to identify potential risks of low flows in a changing climate affecting cooling water availability at a regional scale across the UK, for three contrasting energy supply scenarios developed as part of the UK Infrastructure Transitions Research Consortium (ITRC) National Infrastructure Assessment (Hall et al., 2012, 2013, 2014, 2015).

The aim of this study is to assess the future freshwater demands of fossil fuel generation capacity with carbon dioxide capture and storage (CCS) against low-flow metrics of freshwater resource availability in a changing climate. Subsequently, the authors ascertain on a regional level whether the sector's demands exceed available resources during low flows in the future. They recap on methods and results from their previous assessments of future cooling water requirements of UK electricity pathways at national (Byers et al., 2014) and regional (Hall et al., 2015; Tran et al., 2014) scales. The authors then detail the calculation of water resource availability at low flows and how river abstractions are licensed using flow statistics. From this, the authors present a comparative assessment of demands against the future available resource. The results and discussion follow a similar structure, concluded by a sensitivity analysis and policy discussion.

\subsection{The need for cooling water in thermal electricity generation}

Thermoelectric power stations with steam cycles require cooling for efficient operation. This cooling is traditionally and most effectively provided by water. In the UK, thermoelectric capacity provides $96 \%$ of electricity supply and is distributed across freshwater rivers, tidal surface waters and coastal regions. Eighteen per cent of the UK's electricity comes from capacity that is either air-cooled or requires negligible cooling, as in the case of open-cycle gas turbines (Byers et al., 2014).

Initially, power stations were cooled through direct cooling heat transfer to flowing water, although in the last few decades there has been much more use of wet cooling towers. These systems generally require much smaller volumes of water, are much less dependent on cooling water temperature and do not result in thermal pollution from water discharges. Wet-tower cooling, however, results in significant evaporative losses, often in the region of $60-90 \%$ of the abstracted volumes, as the majority of cooling is provided by evaporative heat transfer. Almost all the power stations on freshwater in the UK now use wet cooling towers.

\subsection{Future electricity generation in the UK, decarbonisation and CCS}

Water use by the electricity sector is coming under increased scrutiny given the growing pressures on water resources from population and economic growth, coupled with increased hydrological variability due to climate change. The electricity sector is also in transition, with pressure from legislation to reduce greenhouse gas emissions (GHGs) as well as policy incentives to facilitate and accelerate the development of low-carbon electricity supply. The Climate Change Act 2008 (2008) requires the UK to reduce GHGs by $80 \%$ on 1990 levels by 2050 and the electricity sector is expected to play a leading role in this emissions reduction. Not only is decarbonisation of the electricity supply expected, but other sectors are increasingly seeking to achieve their own emissions reductions through increased electrification.

CCS is a system of technologies that sequester carbon dioxide from a process and store it safely. Common use of the term implies that the carbon dioxide is captured before or after fossil fuel combustion and stored in geological formations over a timescale long enough so as to mitigate anthropogenic global warming. All the main processes of CCS are used in various industries globally. However, demonstration of the system in operation to mitigate GHGs from fossil fuel power plants is only at pilot and demonstration stages in all cases but one (Global CCS Institute, 2013). Boundary Dam in Canada is the only commercial operation, capturing $1 \mathrm{Mt} \mathrm{CO}_{2} /$ year from $100 \mathrm{MW}_{\mathrm{e}}$ of electricity generation. Nonetheless, CCS potentially offers a widely deployable and possibly affordable intervention to mitigating GHGs. However, the carbon dioxide capture equipment imposes a parasitic load on a power station. This results in whole station cooling demands ranging from 26 to $140 \%$ higher than unabated generation, with commensurate cooling water requirements (Delgado, 2012; IEAGHG, 2011; Macknick et al., 2011, 2012a; PB, 2012; Zhai and Rubin, 2010; Zhai et al., 2011).

\subsection{Climate change impacts and competing demands for freshwater}

Global warming is expected to have a range of varied impacts on the climate of the UK. Warmer and wetter winters will be interspersed by hotter and drier summers (Murphy et al., 2009). Reductions in summertime rainfall run-off and growing likelihood of drought are expected. The Future Flows Hydrology 2050 project (Prudhomme et al., 2012, 2013) estimates summer run-off changes in the range of +20 to $-80 \%$ for the central estimate, with the greatest changes in 
the north and west. Large reductions are also expected in the south and east during the autumn period. As summarised by the UK Climate Change Risk Assessment for the Water Sector (Rance et al., 2012), several other studies also indicate that summer flows are likely to decrease (Christierson et al., 2012; Lopez et al., 2009; New et al., 2007; Wilby et al., 2006).

Growing demands for water from some sectors will also increase competition for scarcer resources. While there are efforts to reduce per-capita demands from public water supply, the UK population is expected to be $25 \%$ higher in 2050 with above-average growth expected in the south-east, London and Midlands areas. Wider global pressures of food and water insecurity may also lead to land-use change and growth in intensive agriculture in the UK (Whitehead et al., 2013), with increased water use from agriculture and contribution to soil moisture deficits. Such upstream catchment processes affect river flows downstream where electricity sector abstractors are usually based, in addition to increasing competition for limited abstraction license volumes.

\subsection{Water abstraction licensing and reliability}

The reliability of the cooling is critical to the security of electricity supply. If using water for cooling, developers must establish that the water source is highly reliable and often seek to obtain water abstraction licenses that permit 'unconstrained' availability of a determined volume of water. However, substantial hydrological variability is present even in mid-latitude hydro-climates such as that of the UK, leading to significant risks from sustained periods of low flows associated with droughts.

Abstractions of water from freshwater bodies are regulated to allow fair allocation of water between competing demands (including municipal water supplies and agriculture, as well as cooling water), at the same time as safeguarding flows for the natural environment. Water resources are licensed by assessing the volumes available at very low flows, which are derived from statistical analysis of the historical record of flows in the catchment, called a flow duration curve (FDC). The FDC is similar to an annual load duration curve for an electricity system, although it is considered over a period long enough to capture the natural hydrological variability experienced over years, and ideally over decades, of climatic variability. Taking very low flow as a benchmark, typically $Q_{99.9}$ which is the flow exceeded $99.9 \%$ of the time, a portion of this flow is reserved to maintain environmental quality (normally $75 \%$ ), while the remainder is licensed for highreliability unconstrained abstraction (normally 25\%) (Figure 1) (EA, 2002). Once this volume is fully licensed, further volumes can be licensed, but are constrained by lower levels of

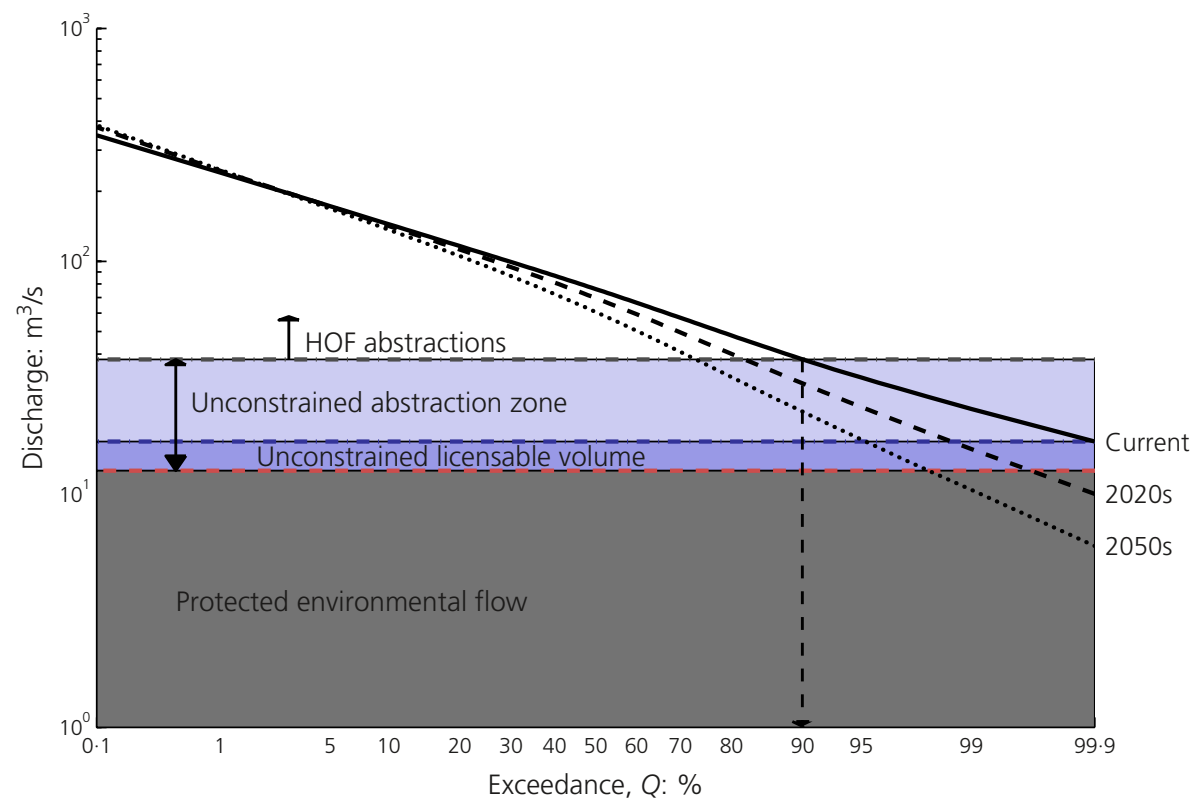

Figure 1. Example FDCs (in this case the River Trent) for current, 2020s and 2050s flows. Shaded areas show the volumes that define the current abstraction regime. HOF, Hands-off flow 
reliability such as the fifth percentile $Q_{95}$, or the tenth percentile $Q_{90}$ as in Figure 1. If the flow falls below this level, called a 'hands off flow' (HOF), these license holders must cease or reduce abstraction in order to maintain reliability for the unconstrained users. Although extremely rare, unconstrained abstractors may also have their abstractions limited by the Secretary of State for the Environment under the Water Resources Act 1991 (1991).

With a changing climate, the profile for the FDC on which licensed abstraction volumes are based will change. Thus, if the same volume is to be available to a user, the reliability of that volume will be lower, as what was historically a first percentile flow may be a fifth percentile flow in the 2020s and a twelfth percentile in the 2050s, for example. Conversely, if one is to maintain the same reliability for a user, the volume of water available at, say, the first percentile will decrease. Given the importance of reliability to the electricity sector, this work takes the second perspective to assess potential volume reduction of high-reliability flows.

\section{Future demands for cooling water}

A variety of electricity generation scenarios has been developed by the UK government, industry and others (CCC, 2010; DECC, 2010; HMG, 2011; NG, 2014) to explore future configurations of the energy mix that deliver the key three objectives of affordability, security of supply and low emissions. In 2013 , in the UK, electricity was supplied from $36 \%$ coal, $27 \%$ gas, 20\% nuclear, 15\% renewables and 2\% others (DECC, 2014). Future mixes will likely include a variety of these sources, with CCS on all coal and most gas and small contributions from imports, hydro and other diverse sources. It is unlikely that any one technology will dominate the whole mix, but it is certainly possible that the mix features a more dominant technology, such as a high proportion of coal and gas with CCS, or nuclear.

\subsection{Future electricity strategies and water use calculation}

Electricity strategies were developed in the combined gas and electricity network (CGEN+) planning model (Chaudry et al., 2008, 2014) and are introduced in Section 2.2. CGEN+ is an optimisation model for energy infrastructure expansion planning on a regional basis. Generation and capacity is spatially split by a 16-busbar electricity network, representing the Great Britain (GB) high-voltage transmission network (Figure S2 in the online supplementary material). Each busbar represents a point at which electrical power is available for transmission or distribution.

Annual water abstraction and consumption was calculated using the framework and model presented by Byers et al. (2014), modified to accommodate regional disaggregation over the 16 busbars. The abstraction and consumption factors used (Table 1) are derived from a variety of sources from the literature (IEAGHG, 2011; Macknick et al., 2012a; PB, 2012; Tzimas, 2011; Zhai and Rubin, 2010; Zhai et al., 2011), given that such data are difficult to obtain from both regulators and industry.

The current distribution of capacity over different water sources and cooling technologies was derived from the data presented by Byers et al. (2014) (section S2 in the online supplementary material). Future cooling water source distributions and locations (section S1 in the online supplementary material) were derived on a busbar-by-busbar basis, taking into consideration the current capacity, planned developments and closures from the DECC energy infrastructure planning portal (TPI, 2012) and EU Large Combustion Plant Directive, the locational legacy of electricity generation in the region (Google and Bing! maps satellite imagery) and recent policy statements such as the CCS roadmap (DECC, 2012a) and the Gas Generation Strategy (DECC, 2012b). The general trend observed and projected is slightly increased coastal-based generation, while the capacity on freshwater is increasingly using hybrid and dry air-cooling.

\begin{tabular}{|c|c|c|c|c|c|c|c|}
\hline $\mathrm{Ml} / \mathrm{GWh}$ & CCGT & Coal & $\mathrm{CCGT}+\mathrm{CCS}$ & Coal+CCS & Waste/biomass & CHP gas & CHP coal \\
\hline \multicolumn{8}{|c|}{ Once through cooling } \\
\hline Abstraction & 43.07 & $102 \cdot 53$ & $81 \cdot 84$ & $194 \cdot 80$ & $132 \cdot 48$ & $25 \cdot 84$ & $61 \cdot 52$ \\
\hline Consumption & $0 \cdot 38$ & 0.43 & 0.72 & $0 \cdot 81$ & 0.95 & $0 \cdot 23$ & 0.23 \\
\hline \multicolumn{8}{|c|}{ Closed-loop wet-tower cooling } \\
\hline Abstraction & 0.97 & $2 \cdot 22$ & 1.92 & $3 \cdot 62$ & $3 \cdot 32$ & 0.58 & $1 \cdot 16$ \\
\hline Consumption & 0.78 & $1 \cdot 81$ & 1.49 & $2 \cdot 71$ & $2 \cdot 69$ & 0.47 & 0.70 \\
\hline
\end{tabular}

Ml/GWh, also equivalent to $1 / \mathrm{kWh}$ and $\mathrm{m}^{3} / \mathrm{MWh}$; CCGT, combined-cycle gas turbine; CHP, combined heat and power Hybrid cooling is assumed to have water use that is on average $65 \%$ of closed-loop wet-tower cooling

Table 1. Summary of abstraction and consumption factors for electricity generation used in the study 

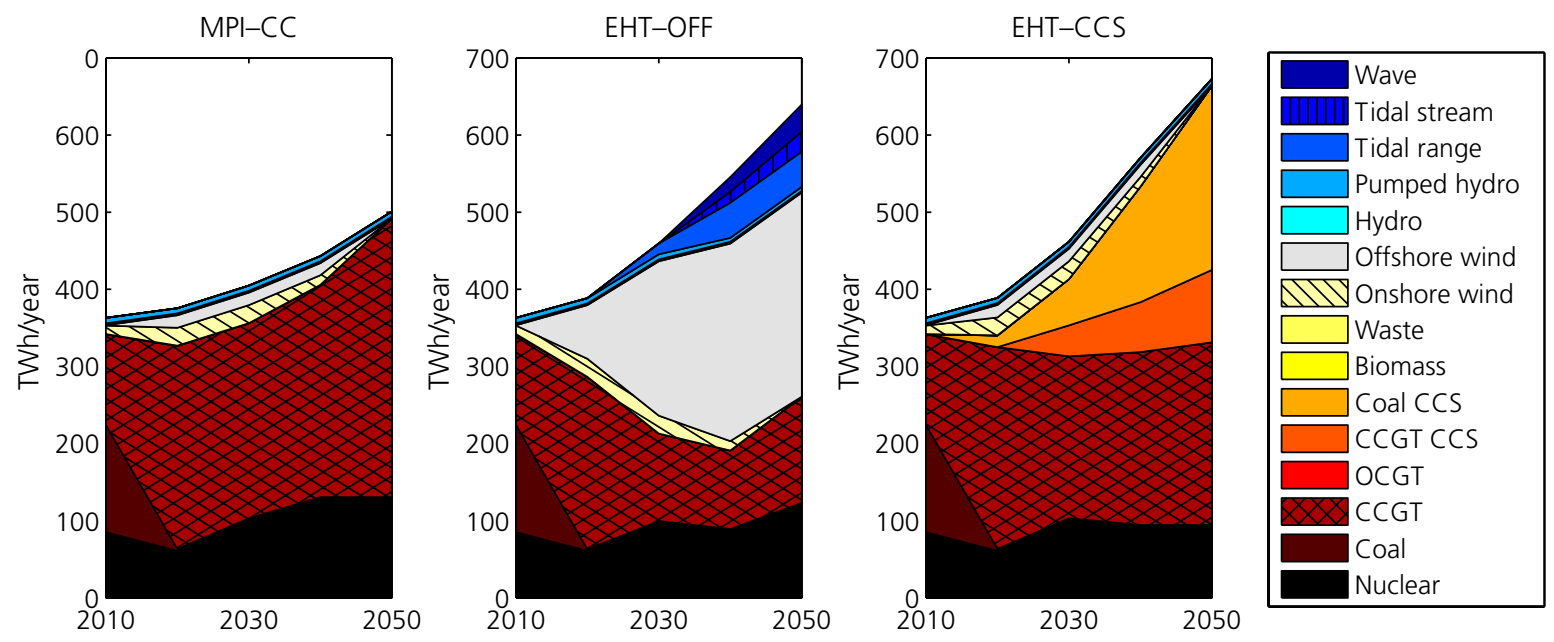

Figure 2. Electricity generation of the three strategies from 2010 to 2050; the shading in the plots is ordered top to bottom the same as in the key

\subsection{Abstraction and consumption of the generation strategies}

Three future generation strategies were chosen for analysis as summarised in Figure 2, based on Hall et al. (2015), MPI-CC is the 'minimal policy intervention strategy' with a rising carbon price floor. It entails no significant demand efficiency improvements and little electrification of heat and transport. The generation mix totalling $506 \mathrm{TWh} /$ year in 2050 is dominated by combined-cycle gas turbine (CCGT) at 73\%, with nuclear power at $26 \%$. Two strategies, electrified heat and transport (EHT)offshore and EHT-CCS, have demand characterised by EHT and thus have an electricity demand that is $35 \%$ higher at $684 \mathrm{TWh} /$ year (also described by Baruah et al. (2014) and Tran et al. (2014)). The EHT-CCS mix is made up by $35 \%$ each of CCGT and coal+CCS, and additionally $14 \%$ each of nuclear and CCGT+CCS. The EHT-offshore strategy has $43 \%$ offshore wind, 20\% CCGT, 18\% nuclear and the remaining 19\% mostly offshore renewables. All strategies have a rising carbon price floor and are further detailed in the supplementary information (S1).

Figure 3 presents water abstraction and consumption by source for the three strategies, aggregated over all 16 busbar regions. Table 2 and Figure 4 present these results on a regional basis for 2010 and 2050, with consumptive use displayed as a proportion of abstraction. Figure 5 is a Sankey diagram of freshwater use in 2050 for the EHT-CCS strategy, disaggregating water use by generation capacity and busbar region. It is an example output of an online web-tool being developed by the ITRC to analyse different strategies (Figure 5 and 6).

EHT-offshore results in the greatest reduction of $89 \%$ and $88 \%$ for the abstraction and consumption of freshwater, respectively, and $83 \%$ and $86 \%$ for tidal water by 2050 . Reductions are distributed through most regions, with only south-west (SW) England and Thames regions projected to see increases in seawater use.

MPI-CC sees $71 \%$ and $74 \%$, and $6 \%$ and $52 \%$ reductions in fresh and tidal water use, respectively, mostly occurring in the Humber/E Midlands, Anglian, Thames and Forth regions. However, seawater abstraction increases by $70 \%$, most substantially in the northwest (NW), SW, SE and Thames regions of England, due to growing nuclear capacity.

The EHT-CCS strategy results in $85 \%$ and $100 \%$, and $34 \%$ and $59 \%$ increases in fresh and tidal water use by 2050 . Very large increases occur in the Humber/E Midlands, Thames, NW England and north-east (NE) Scotland regions due to concentrations of CCS capacity; only 7\% of water use occurs elsewhere. In particular, E Midlands/Humber and Deeside/NW regions see abstractions rising to 105000 and $89000 \mathrm{Ml} /$ year, respectively, with consumptive losses in the order of $65 \%$ of abstractions. The strategy also results in significant increases in both tidal and seawater use, $59 \%$ and $122 \%$, respectively, in particular due to the nuclear and coal+CCS capacity. For tidal water, large increases are projected in Humber/E Midlands and Thames regions, while Thames and Solway and Tweed regions may expect large increases in seawater use.

Worth noting in Figure 3 is the dip in water use, particularly freshwater, observed in 2020 due to the closure of capacity from the EU Large Combustion Plant Directive and CCS capacity not yet being available, similarly observed by Byers et al. (2014). Looking across the strategies, EHT-CCS is consistently the most freshwater intensive, although in the cases of EHT-CCS and 

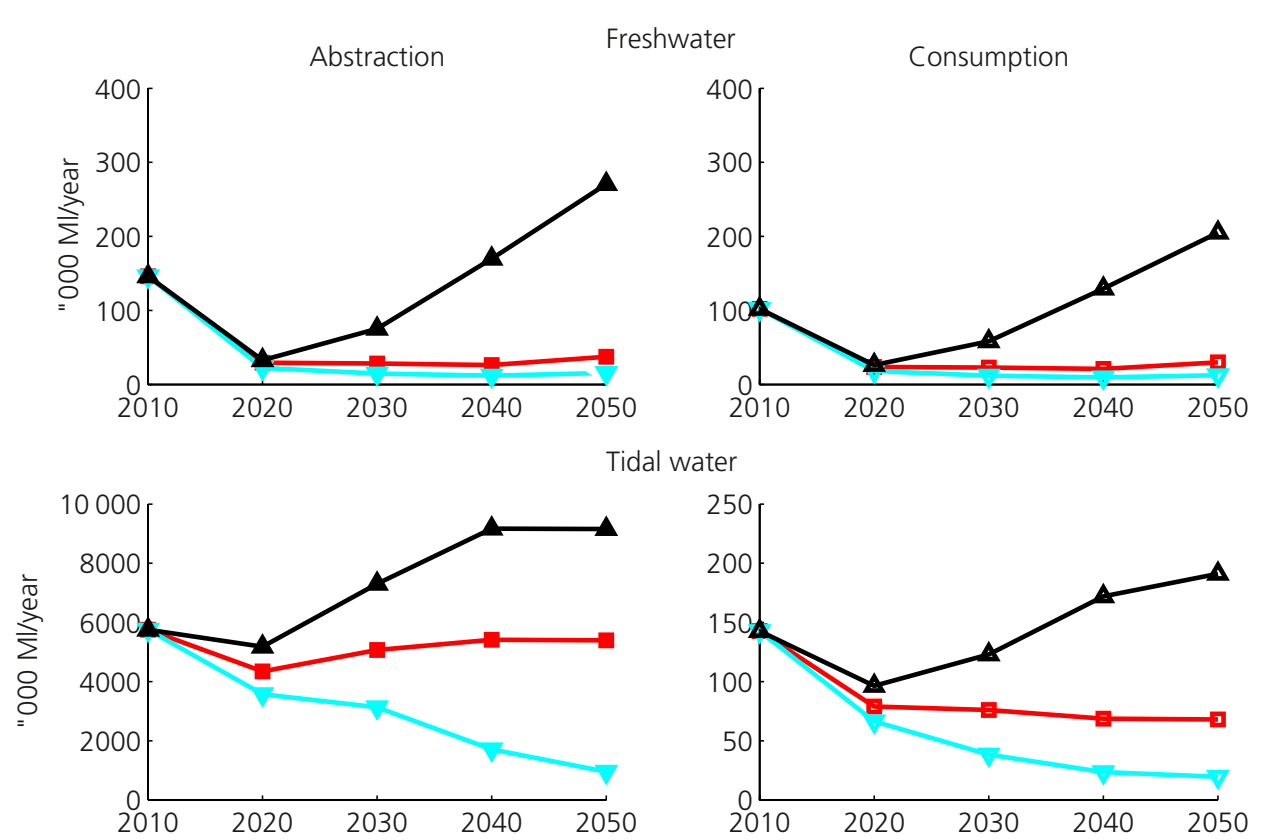

Seawater

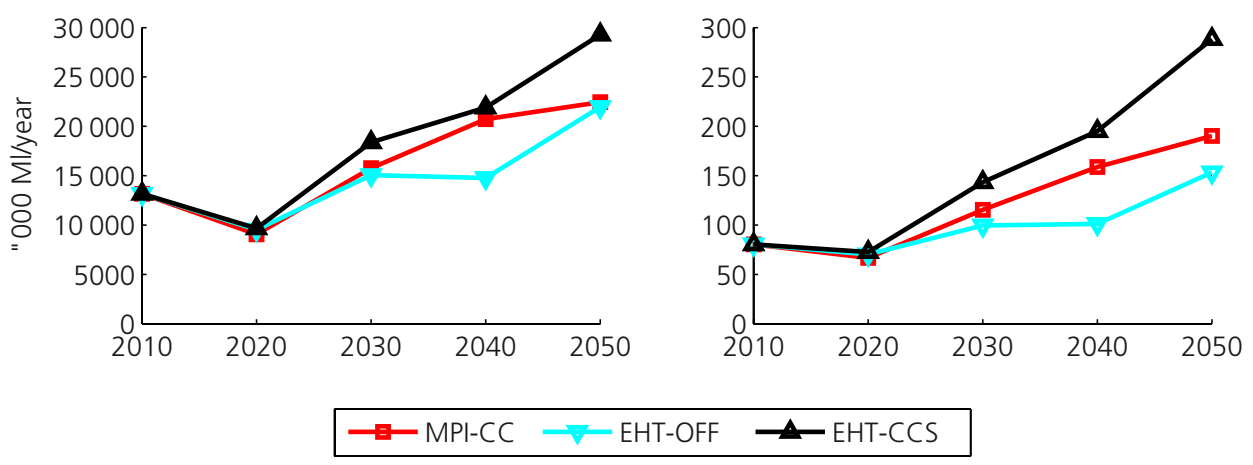

Figure 3. Abstraction and consumption, for all water sources

aggregated across all busbar regions

EHT-offshore, the elevated seawater use is largely due to the increased capacity of nuclear power. Across the busbar regions, for MPI-CC and EHT-CCS, Humber/E Midlands, Thames and NW England areas are repeatedly projected to see large increases in both fresh and tidal water abstractions. SW England will also have elevated seawater use in strategies with high nuclear generation (Figure 6).

Finally, the EHT-CCS strategy has a high amount of CCS capacity that will operate at a high load factor alongside nuclear power. In strategies with greater proportions of nuclear and/or renewable power and intermediate levels of CCS, the former would be prioritised and the CCS capacity would likely operate at lower load factors. This would reduce the instantaneous demands at average load factor presented in Table 5, but clearly would not reduce the demands at $100 \%$ load factor.

\section{Assessment framework}

\subsection{Overview}

Cooling water demands vary through time, depending on the load at each power plant, as does the availability of water in rivers. Therefore, in addition to presenting thermoelectric water abstraction and consumption on an annual basis, the authors present instantaneous peak loads. They compare these different demands against regional projections of water availability at low flows under a changing climate (Figure 7).

\subsection{Future water availability under climate change}

Freshwater resource availability is determined in this study by assessing statistical measures of low flows at various flow gauges in the busbar regions across the UK. For each 


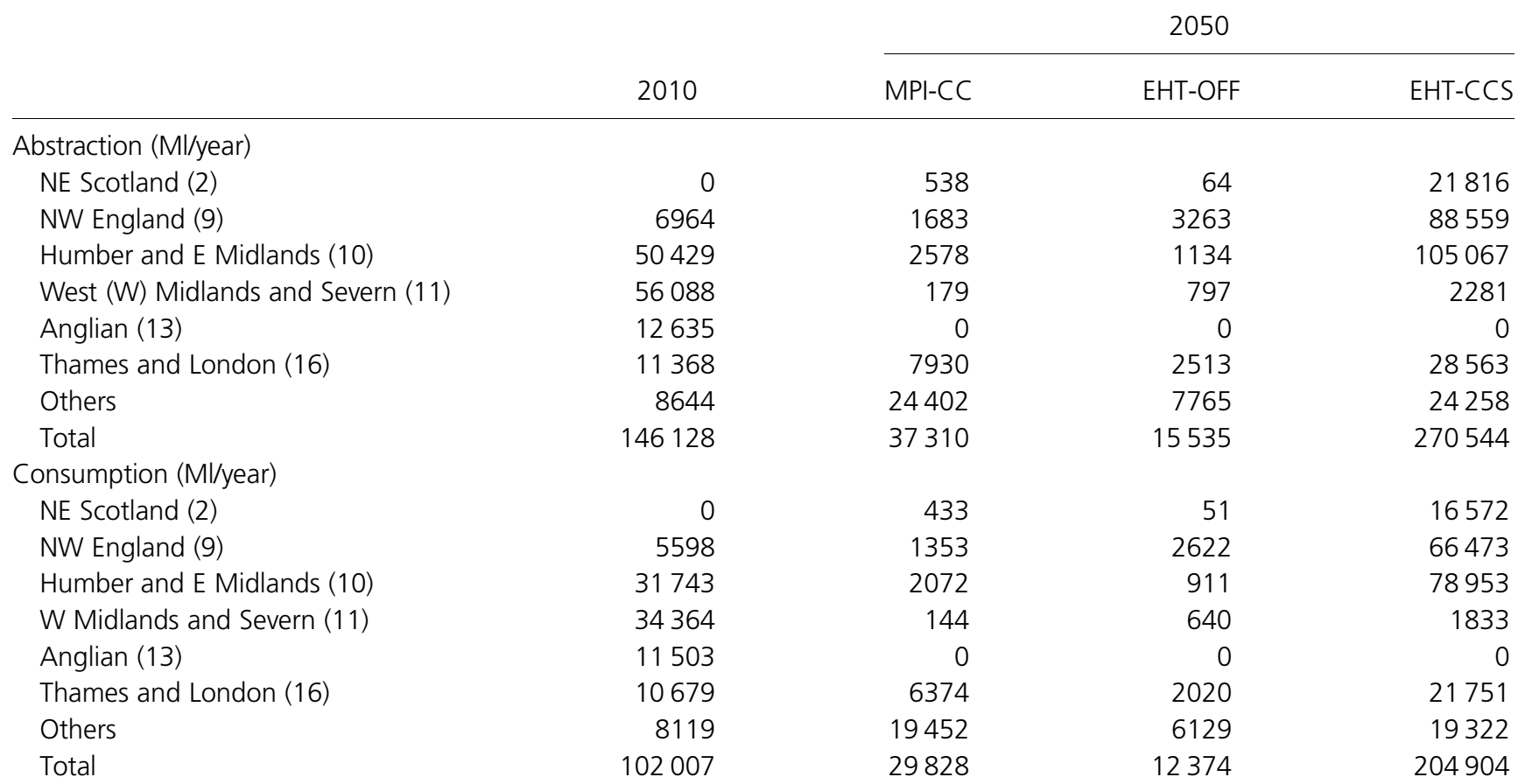

Table 2. Freshwater abstraction and consumption in 2010 and as projected for 2050 for the three energy strategies

busbar, these low flow metrics are used to calculate the volume of water available for licensed abstraction, of which a portion is attributed to the electricity sector.

The $Q_{95}$ and $Q_{99}$ values are fifth and first percentile statistics from the FDC, which is a distribution of flows by percentile over a set time period; this is normally the historical record of flows in the river. River gauges with $Q_{95}$ flows above $5.0 \mathrm{~m}^{3} / \mathrm{s}$ (432 Ml/d) were identified in the National River Flow Archive (CEH, 2012), as this was a level considered to be sufficient for a small- to medium-sized $500 \mathrm{MW}_{\mathrm{e}}$ coal-fired power station with CCS and closed-loop wet tower cooling. This is calculated in the supplementary information (S3.2) by rearranging Equation 1. The licensable flow on river $i, Q_{\mathrm{L}}$, is determined by multiplying percentiles on the FDC (i.e. $Q_{95}, Q_{99}$ ) by factors that reflect the abstraction sensitivity of the water body at those flow percentiles, called abstraction sensitivity bands, $A_{95}$ (EA, 2013). This gives the licensable volume, $Q_{\mathrm{L}}$, of which the electricity sector holds a portion of the abstraction licenses, $S_{\mathrm{e}}$. The proportion of licences held by the sector is assumed from the recent proportion held on a regional basis (EA, 2012). In most cases, they are rounded up to the next $10 \%$ and are considered to be the optimistic licence holding. The abstraction available to the electricity sector, $Q_{\mathrm{e}}$ at $Q_{95}$, is hence the $Q_{95}$ flow multiplied by the abstraction sensitivity factor and the portion of licenses held by the sector

1. $Q_{\mathrm{e} 95}=Q_{95} A_{95} S_{\mathrm{e}}$

The total resource available to the sector in a busbar region is the sum of $Q_{\mathrm{e}}$ from $r$ suitably sized rivers in region $b$

2. $Q_{\mathrm{e} 95}^{b}=\sum_{i=1}^{r} Q_{\mathrm{e} 95}^{i}$

Future flows $(Q)$ for a medium emissions scenario and resultant 2020s and 2050s climates were determined using a hydrological water resources model for Great Britain (Leathard and Kilsby, ongoing work at Newcastle University). The model is an 11-parameter lumped conceptual model of daily mean discharge established for 72 catchments across the UK. It is calibrated using a machine-learning algorithm (Wall, 1996) that minimises differences between mean, variance and correlation of historical and simulated observations using a single representative metric from Gupta et al. (2009). The procedure rejects solutions with less than $95 \%$ agreement or more than $5 \%$ difference in water balance when comparing between 

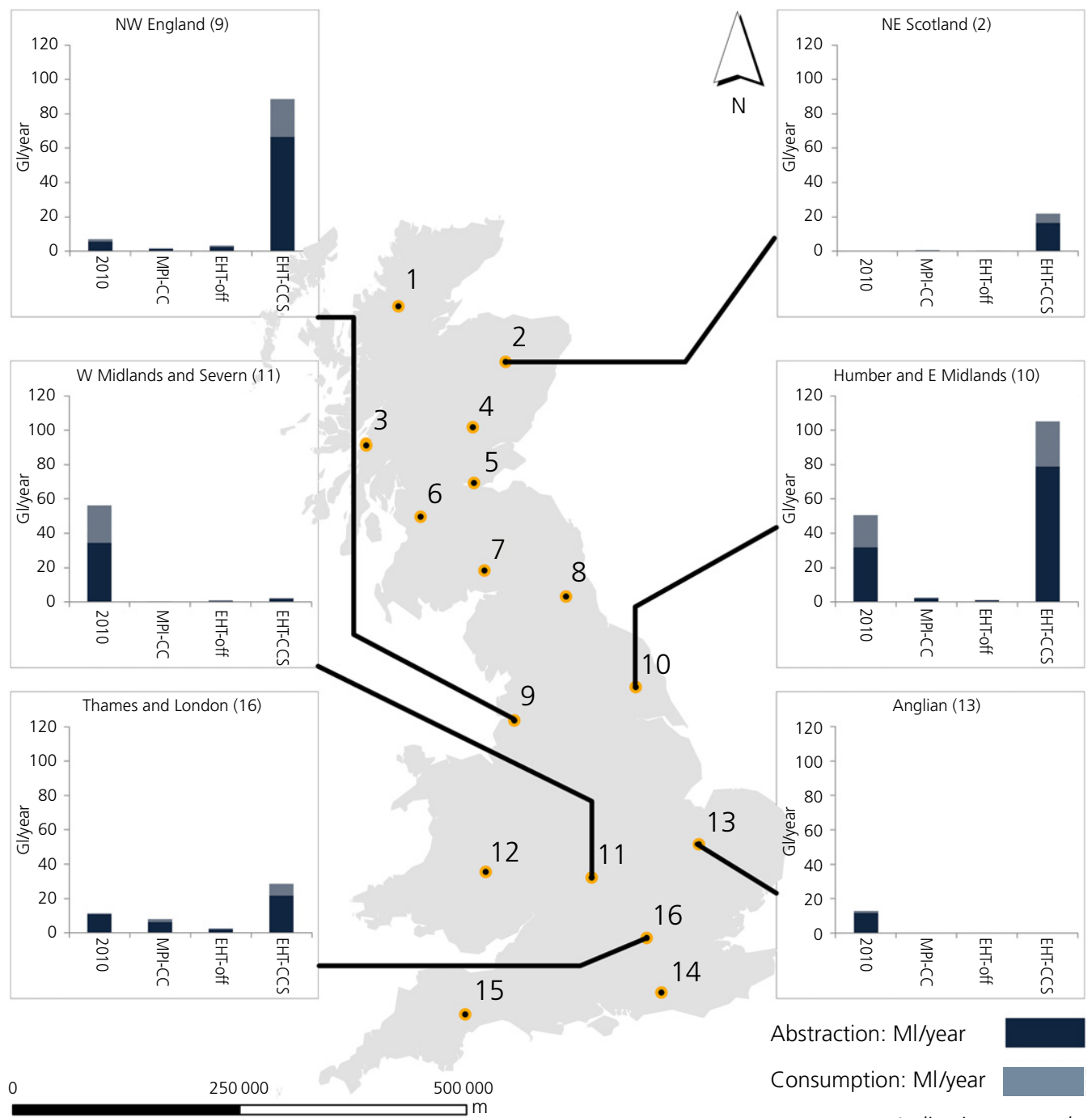

Indicative map only (c) Crown copyright

Figure 4. Regional freshwater abstraction (dark + light), of which consumption (dark) for all three strategies in 2050 in Gl per year

observed and modelled series of flow. Observed series of daily rainfall and potential evapotranspiration (PET) were derived from UK Met Office datasets (Perry and Hollis, 2005a, 2005b) and flow data were taken from the National River Flow Archive (CEH, 2012) for the period 1961-2002. Future river flows were generated by using inputs of UKCP09 weather generator (Jones et al., 2009; Kilsby et al., 2007) time series of rainfall and PET for the Special Report on Emissions Scenarios (SRES) A1B medium emissions scenario in the 2020s, 2050s and 2080s (Nakicenovic and Swart, 2000). Results are detailed further in the supplementary information (S2.4).

\subsection{Regional water demand and availability assessment}

Regional cooling water demand and availability is assessed on two temporal dimensions: annualised demands to determine the long-term trend in absolute water use (Section 2) and instantaneous demands to assess the risk specifically at low flows (Sections 4.1 and 4.2). Annual demands are calculated by aggregating water use of the electricity sector over a year at each decadal time step. Assumptions about the intra-annual variation may be taken for more detailed analysis; for example, by applying monthly load factors. The low flow demands are 


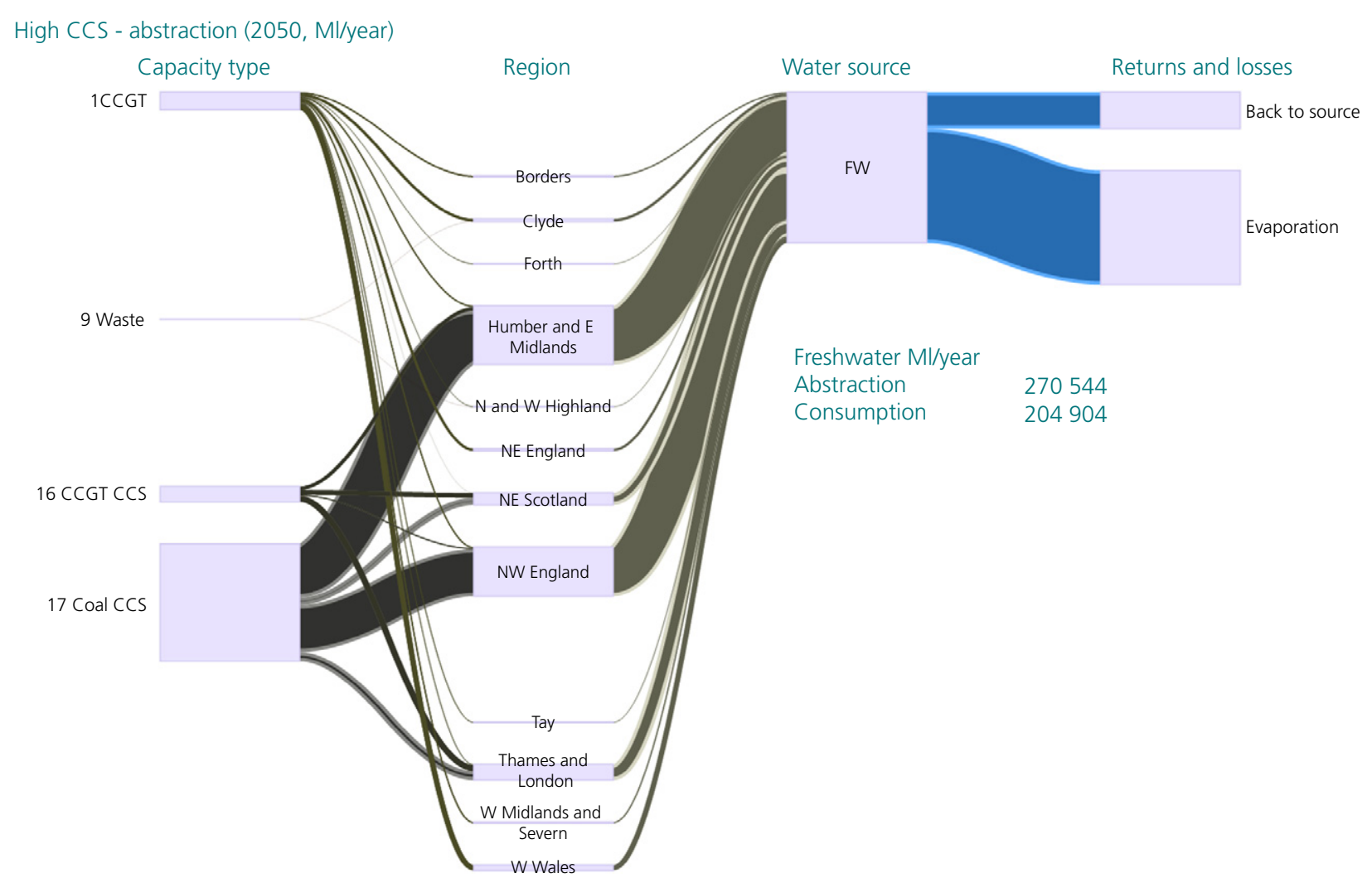

Figure 5. Sankey diagram of 2050 freshwater use by thermoelectric generation for the EHT-CCS strategy, where the line thickness is proportional to water use. Screenshot of ITRC web-based Sankey tool (Bostock, 2012; Counsell, 2013)

calculated with load factors to determine the volume of instantaneous or daily abstractions according to different levels of power station operation (the load). For this study, low flow demands are assessed on an instantaneous basis $\left(\mathrm{m}^{3} / \mathrm{s}\right)$ at average load factors for each technology in the strategy.

\section{Water availability and future demands}

\subsection{Abstraction demands against water availability at $Q_{95}$ and $Q_{99}$}

The results of the hydrological water resource modelling indicate significant reductions in flows at $Q_{95}$ and $Q_{99}$ due to climate change. The reductions in median flows at $Q_{95}$ and $Q_{99}$ are presented for the A1B SRES medium emissions climate scenario (Table 3).

The impacts of abstraction at low flows are assessed by calculating the rate of instantaneous abstraction for each strategy in each region at average and $100 \%$ load factors. This is presented in Table 4 at $Q_{95}$ and $Q_{99}$ flows in a 2050s climate against projected abstractions in 2050. The same table is also presented in the supplementary information for the 2020s and 2080s. Annual average capacity factors for CCS capacity are $69 \%$ in 2020 and between 67 and $68 \%$ in 2050. Seasonal capacity factors vary; $33-79 \%$ in summer, $55-80 \%$ in winter and $77-80 \%$ for the intermediate seasons in 2050 depending on capacity type. While summer factors are typically lower, the lowest flows typically occur in the intermediate season in autumn after a dry summer.

In the majority of regions, there is sufficient resource for only a small volume of abstractions, even at very low flows. Three regions in particular, however, show cause for concern: 9, NW England; 10, Humber and E Midlands; and 16, Thames and London regions. The former two have high concentrations of CCS capacity in the EHT-CCS strategy. Subsequently, demands for water resource greatly exceed the available freshwater by 2050 , even without the impacts of climate change. This is an important conclusion in itself, given the uncertainties that are inevitably present in projections of future flows. 


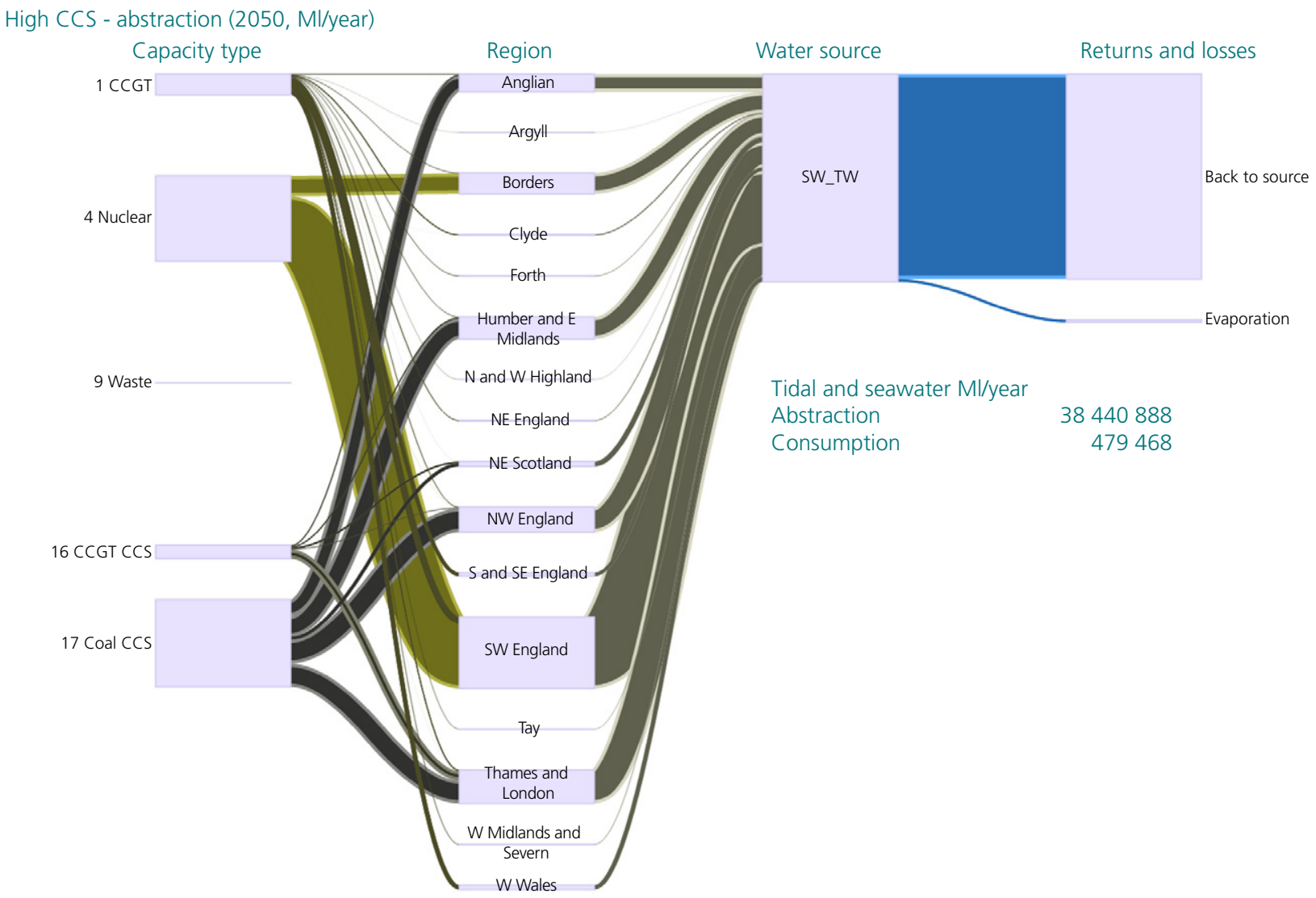

Figure 6. Sankey diagram of 2050 tidal and seawater use by thermoelectric generation for the EHT-CCS strategy, where the line thickness is proportional to water use. NB: the scale of flows is $100 \times$ greater than those shown in Figure 5 for freshwater. Screenshot of ITRC web-based Sankey tool (Bostock, 2012; Counsell, 2013)
Freshwater shortages and limited availability of abstraction licenses could lead to an elevated concentration of power stations on the tidal stretches of the Trent and in the Humber and Mersey estuaries. For these two regions, it has been assumed that $30-35 \%$ of CCGT and $35-40 \%$ of coal-fired capacity are on freshwater, with similar proportions on tidal water. This analysis confirms that a much higher amount of the demand will have to come from tidal or seawater to ensure sustainable abstraction at low flows in these regions, even with power plants holding some $50 \%$ of licensed abstraction volume. As for the Thames and London region, where power plants are assumed to hold only $10 \%$ of the licensed freshwater volume and whereby only $10 \%$ of CCGT and coal-fired capacity is based on freshwater, there is simply no available resource at very low flows. While it is unlikely that any capacity is developed on freshwater west of London, modelling a small proportion of $10 \%$ illustrates the sensitivity of this region to freshwater-based capacity development. Other regions, particularly in the north of England and south of Scotland, may be able to accommodate extra CCS capacity development on freshwater while not being located too far from the demand centres or CCS infrastructure. Further research into regional demographic trends and CCS technology deployment may help identify these alternative options.

\subsection{Peak abstraction demands}

The final aspect of the analysis evaluates the instantaneous demands in the EHT-CCS strategy assuming average and 100\% load factor in regions 9,10 and 16 (Table 5). For strategies with EHT, such as EHT-CCS, alongside population growth in these regions, peak electricity demands are expected to more than double by 2050 (Tran et al., 2014). Hence, when combined with the growing demands of CCS and the diminishing water resource, in almost all cases both the average load factor and the $100 \%$ load factor abstraction demands exceed the available $Q_{\text {e99 }}$ resource in 2050 . Hence, it is important that abstraction licensing and planning applications for CCS-enabled generation capacity in the 2030s consider the impacts of climate change on water resources in the 2050s and beyond. While long-term 


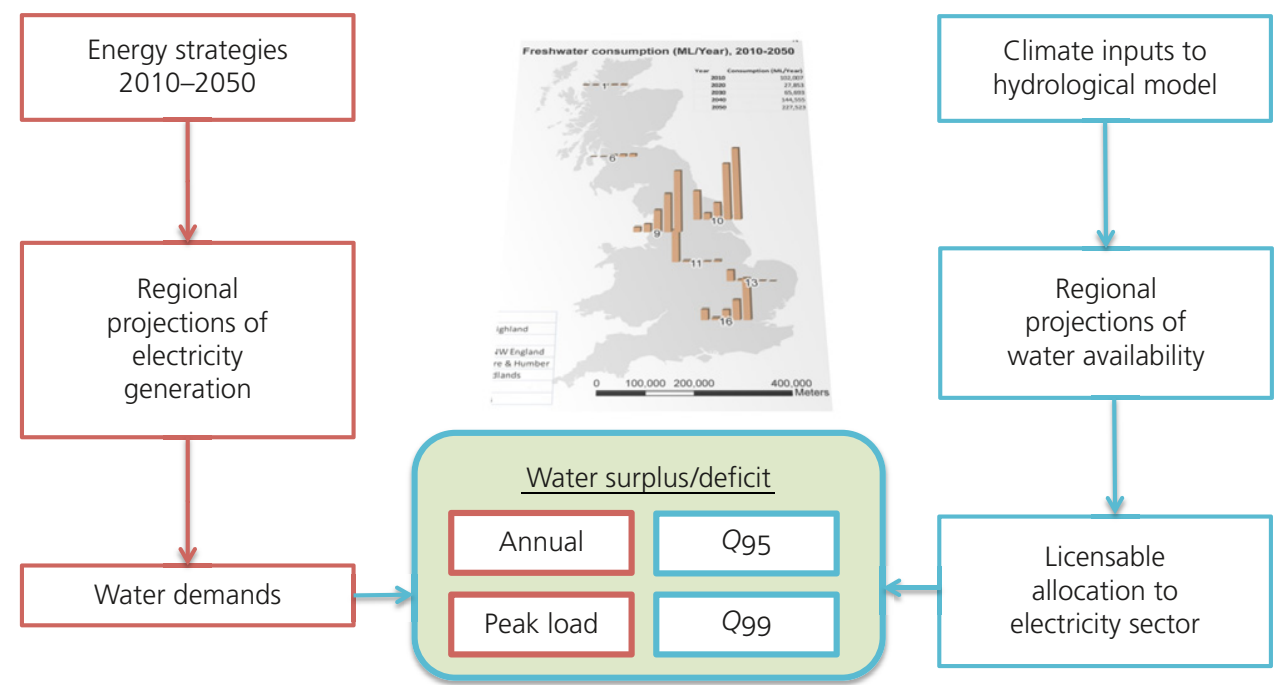

Figure 7. Assessment framework diagram

\begin{tabular}{|c|c|c|c|c|c|c|c|c|c|}
\hline & & \multirow{2}{*}{$\begin{array}{c}\Sigma Q_{95} \\
\text { hist.: } \\
\mathrm{m}^{3} / \mathrm{s}\end{array}$} & \multicolumn{3}{|c|}{$Q_{95}$ Available resource change: \% } & \multirow{2}{*}{$\begin{array}{c}\Sigma Q_{99} \\
\text { hist.: } \\
\mathrm{m}^{3} / \mathrm{s}\end{array}$} & \multicolumn{3}{|c|}{$Q_{99}$ Available resource change: \% } \\
\hline \multicolumn{2}{|c|}{ Region $(b)$} & & $2020 s$ & 2050s & $2080 s$ & & $2020 s$ & 2050s & $2080 s$ \\
\hline 1 & $\mathrm{~N}$ and $\mathrm{W}$ Highlands & $36 \cdot 6$ & -8 & -20 & -19 & $21 \cdot 6$ & -12 & -30 & -32 \\
\hline 2 & NE Scotland & $53 \cdot 7$ & -19 & -34 & -44 & $39 \cdot 0$ & -22 & -38 & -49 \\
\hline 3 & Argyll & 0.0 & - & - & - & $0 \cdot 0$ & - & - & - \\
\hline 4 & Tay & $43 \cdot 5$ & -12 & -26 & -35 & $31 \cdot 7$ & -14 & -32 & -44 \\
\hline 5 & Forth & $5 \cdot 7$ & -10 & -22 & -31 & $3 \cdot 9$ & -15 & -30 & -43 \\
\hline 6 & Clyde & $19 \cdot 4$ & -10 & -22 & -31 & $15 \cdot 3$ & -15 & -30 & -43 \\
\hline 7 & Borders & $24 \cdot 3$ & -19 & -40 & -50 & $18 \cdot 1$ & -15 & -39 & -51 \\
\hline 8 & NE England & $12 \cdot 4$ & -25 & -44 & -53 & $9 \cdot 5$ & -31 & -50 & -61 \\
\hline 9 & NW England & $13 \cdot 4$ & -23 & -42 & -50 & $9 \cdot 1$ & -39 & -66 & -78 \\
\hline 10 & Humber and E Midlands & $43 \cdot 8$ & -22 & -45 & -55 & $34 \cdot 6$ & -24 & -49 & -58 \\
\hline 11 & W Midlands and Severn & $19 \cdot 9$ & -20 & -41 & -50 & $15 \cdot 5$ & -23 & -46 & -56 \\
\hline 12 & W Wales & $11 \cdot 2$ & -34 & -60 & -71 & $7 \cdot 4$ & -39 & -66 & -78 \\
\hline 13 & Anglian & 0.0 & - & - & - & 0.0 & - & - & - \\
\hline 14 & S and SE England & 0.0 & - & - & - & 0.0 & - & - & - \\
\hline 15 & SW England & $11 \cdot 9$ & -17 & -31 & -40 & $9 \cdot 8$ & -20 & -36 & -45 \\
\hline \multirow[t]{3}{*}{16} & Thames and London & $7 \cdot 5$ & -41 & -70 & -81 & $3 \cdot 6$ & -49 & -77 & -86 \\
\hline & Sum & $303 \cdot 8$ & & & & $219 \cdot 5$ & & & \\
\hline & Mean, $\Delta: \%$ & & -21 & -40 & -48 & & -25 & -47 & -57 \\
\hline
\end{tabular}

$\Delta(\%)$ : 0 to $-20 \%,-21$ to $-40 \%,-41$ to $-60 \%,-61$ to $-80 \%,<-81 \%$

Table 3. Changes in water resource in the rivers with $Q_{95}$ above $5 \mathrm{~m}^{3} / \mathrm{s}$, calculated by the hydrological model

annual volumes abstracted may not present a problem, it may be challenging to operate at full capacity during periods of drought without relaxation of abstraction regulations and water allocation trading. The authors also note that restrictions in one region may increase pressure on other regions to increase electricity generation and hence increase abstractions. 


\begin{tabular}{|c|c|c|c|c|c|c|c|c|c|c|}
\hline \multirow[b]{3}{*}{ BB } & \multirow[b]{3}{*}{ Region (b) } & \multirow{3}{*}{$\begin{array}{l}\text { Main } \\
\text { rivers (i) }\end{array}$} & \multirow{3}{*}{$\begin{array}{c}\Sigma Q_{95}: \\
\mathrm{m}^{3} / \mathrm{s}\end{array}$} & \multicolumn{3}{|c|}{ Available resource } & \multirow{2}{*}{\multicolumn{4}{|c|}{$\begin{array}{r}\text { Abstraction: } \mathrm{m}^{3} / \mathrm{s} \\
2050\end{array}$}} \\
\hline & & & & \multirow{2}{*}{$\frac{\text { Current }}{Q_{\text {e95 }}}$} & \multicolumn{2}{|c|}{ 2050s } & & & & \\
\hline & & & & & $Q_{\text {e95 }}$ & $Q_{\text {e99 }}$ & 2010 & MPI-CC & EHT-OFF & EHT-CCS \\
\hline 1 & $\begin{array}{l}\mathrm{N} \text { and } \mathrm{W} \\
\text { Highlands }\end{array}$ & $\begin{array}{l}\text { Lochy } \\
\text { Conon } \\
\text { Beauly } \\
\text { Ewe }\end{array}$ & $36 \cdot 6$ & $1 \cdot 1$ & 0.9 & 0.5 & 0.00 & $0 \cdot 10$ & 0.01 & 0.03 \\
\hline 2 & NE Scotland & $\begin{array}{l}\text { Spey } \\
\text { Ness } \\
\text { Don }\end{array}$ & $53 \cdot 7$ & $1 \cdot 6$ & $1 \cdot 1$ & 0.7 & 0.00 & 0.09 & 0.21 & 0.94 \\
\hline 3 & Argyll & & 0.0 & $0 \cdot 0$ & 0.0 & 0.0 & 0.00 & 0.00 & 0.00 & 0.00 \\
\hline 4 & Tay & Tay & $43 \cdot 5$ & $1 \cdot 3$ & 1.0 & 0.6 & 0.00 & 0.06 & 0.01 & 0.03 \\
\hline 5 & Forth & Forth & $5 \cdot 7$ & $0 \cdot 2$ & 0.1 & $0 \cdot 1$ & 0.00 & 0.05 & 0.03 & 0.05 \\
\hline 6 & Clyde & $\begin{array}{l}\text { Clyde } \\
\text { Leven }\end{array}$ & $19 \cdot 4$ & 0.6 & 0.5 & $0 \cdot 3$ & 0.00 & $0 \cdot 28$ & 0.09 & 0.23 \\
\hline 7 & Borders & $\begin{array}{l}\text { Tweed } \\
\text { Eden }\end{array}$ & $24 \cdot 3$ & 0.7 & $0 \cdot 4$ & $0 \cdot 3$ & 0.00 & 0.02 & 0.07 & 0.05 \\
\hline 8 & NE England & $\begin{array}{l}\text { Tyne } \\
\text { Wear } \\
\text { Tees }\end{array}$ & $12 \cdot 4$ & 0.7 & 0.4 & $0 \cdot 3$ & 0.00 & 0.68 & $0 \cdot 14$ & $0 \cdot 17$ \\
\hline 9 & NW England & $\begin{array}{l}\text { Eden Mersey } \\
\text { Dee }\end{array}$ & $13 \cdot 4$ & 0.4 & 0.2 & $0 \cdot 1$ & 0.08 & $0 \cdot 11$ & $0 \cdot 10$ & $3 \cdot 13$ \\
\hline 10 & $\begin{array}{l}\text { Humber and } \\
\text { E Midlands }\end{array}$ & $\begin{array}{l}\text { Aire } \\
\text { G. Ouse } \\
\text { Trent }\end{array}$ & $43 \cdot 8$ & 3.8 & $2 \cdot 1$ & $1 \cdot 6$ & $1 \cdot 76$ & $0 \cdot 10$ & $0 \cdot 17$ & $4 \cdot 14$ \\
\hline 11 & $\begin{array}{l}\text { W Midlands } \\
\text { and Severn }\end{array}$ & Severn & 19.9 & 1.5 & 0.9 & 0.6 & $2 \cdot 05$ & 0.01 & 0.03 & 0.05 \\
\hline 12 & W Wales & Wye & $11 \cdot 2$ & 0.4 & 0.2 & 0.1 & $0 \cdot 00$ & $0 \cdot 13$ & 0.05 & $0 \cdot 20$ \\
\hline 13 & Anglian & - & 0.0 & 0.0 & 0.0 & 0.0 & 0.65 & 0.00 & 0.00 & 0.00 \\
\hline 14 & $\mathrm{~S}$ and SE England & - & 0.0 & $0 \cdot 0$ & 0.0 & 0.0 & 0.36 & 0.00 & 0.00 & 0.00 \\
\hline 15 & SW England & $\begin{array}{l}\text { Test } \\
\text { Avon }\end{array}$ & 11.9 & 0.5 & $0 \cdot 4$ & $0 \cdot 3$ & $0 \cdot 15$ & 0.00 & 0.00 & 0.00 \\
\hline 16 & Thames and London & $\begin{array}{l}\text { Thames } \\
\text { Sum }\end{array}$ & $\begin{array}{r}7.5 \\
303.8\end{array}$ & $\begin{array}{r}0 \cdot 1 \\
13 \cdot 0\end{array}$ & $\begin{array}{l}0 \cdot 0 \\
8 \cdot 1\end{array}$ & $\begin{array}{l}0 \cdot 0 \\
5 \cdot 5\end{array}$ & $\begin{array}{l}0.62 \\
5 \cdot 67\end{array}$ & $\begin{array}{l}0.22 \\
1.85\end{array}$ & $\begin{array}{l}0.08 \\
1.00\end{array}$ & $\begin{array}{l}0.96 \\
9.98\end{array}$ \\
\hline
\end{tabular}

Future abstraction is within resource constraints

Future abstraction is equal to 2050s $Q_{\text {e99 }}$

Future abstraction exceeds 2050s $Q_{\text {e9g }}$ and is smaller than or equal to $Q_{e 95}$

Future abstraction exceeds 2050s $Q_{e 99}$ and $Q_{e 95}$

Future abstraction exceeds 2050s $Q_{e 99}$ and $Q_{e 95}$, and current $Q_{e 95}$

Table 4. Water resource availability at $Q_{95}$ and $Q_{99}$ both currently and in the 2050s, compared with current and projected abstrac-

tions in 2050

\subsection{Sensitivity analysis}

A sensitivity analysis was performed to test the sensitivity to percentage of capacity allocated to freshwater in busbars 9,10 and 16 and the sensitivity to the levels of hybrid or wet tower cooling on freshwater.
Figure 8 presents the effect of the total GB freshwater consumption when the freshwater capacity on either busbar 9, 10 or 16 is adjusted between 0 and $50 \%$. The percentage is the proportion of all the capacity in that busbar, the rest of which is tidal and seawater or air-cooled, as explained 


\begin{tabular}{|c|c|c|c|c|c|c|c|c|c|c|c|c|c|c|c|}
\hline \multirow[b]{3}{*}{$\mathrm{m}^{3} / \mathrm{s}$} & \multicolumn{5}{|c|}{ 9, NW England } & \multicolumn{5}{|c|}{ 10, Humber and E Midlands } & \multicolumn{5}{|c|}{ 16, Thames and London } \\
\hline & \multicolumn{3}{|c|}{ Resource } & \multicolumn{2}{|c|}{ Demand } & \multicolumn{3}{|c|}{ Resource } & \multicolumn{2}{|c|}{ Demand } & \multicolumn{3}{|c|}{ Resource } & \multicolumn{2}{|c|}{ Demand } \\
\hline & $Q_{95}$ & $Q_{e 95}$ & $Q_{e 99}$ & LF & $100 \%$ & $Q_{95}$ & $Q_{\text {e95 }}$ & $Q_{\text {e99 }}$ & $\mathrm{LF}$ & $100 \%$ & $Q_{95}$ & $Q_{e 95}$ & $Q_{\text {e99 }}$ & LF & $100 \%$ \\
\hline 01 & 39 & $0 \cdot 4$ & 0 & & & & $3 \cdot 83$ & & & & & $0 \cdot 11$ & & 71 & \\
\hline 2020 & 10.43 & $0 \cdot 31$ & $0 \cdot 17$ & 0.53 & 0.92 & 33.97 & 2.97 & $2 \cdot 29$ & 0.38 & 1.03 & 4.44 & 0.07 & 0.03 & 0.05 & $0 \cdot 16$ \\
\hline 2050 & 7.79 & 0.23 & 0.09 & 3.13 & $4 \cdot 31$ & 23.94 & 2.09 & 1.56 & $4 \cdot 14$ & $5 \cdot 87$ & 2.29 & 0.03 & 0.01 & 0.96 & 1.57 \\
\hline
\end{tabular}

Table 5. Comparison of $Q_{e 95}$ and $Q_{e 99}$ flows with abstraction demands at average and $100 \%$ load factors

in Section 2.1. For busbar 16 (Thames and London), there is little potential to reduce abstraction given the current level of only $10 \%$, compared with busbars 9 and 10 , whose current capacity is 35 and $40 \%$ on freshwater. Hence, nationwide freshwater abstractions could be reduced significantly by a third to a half by reducing the capacity on freshwater in busbars 9 and 10 .

In the second sensitivity test, the authors varied the penetration of hybrid cooling on freshwater capacity between 0 and $90 \%$ in 2050 , compared with the current penetration of $5 \%$ and the modelled assumption of $30 \%$ by 2050 (Figure 9). In the EHT-CCS strategy, each additional $10 \%$ of hybrid cooling (in the place of wet tower cooling) is estimated to save $10500 \mathrm{Ml}$ of water per year. This is clearly much greater than for the other strategies given the higher water intensity of the strategy.

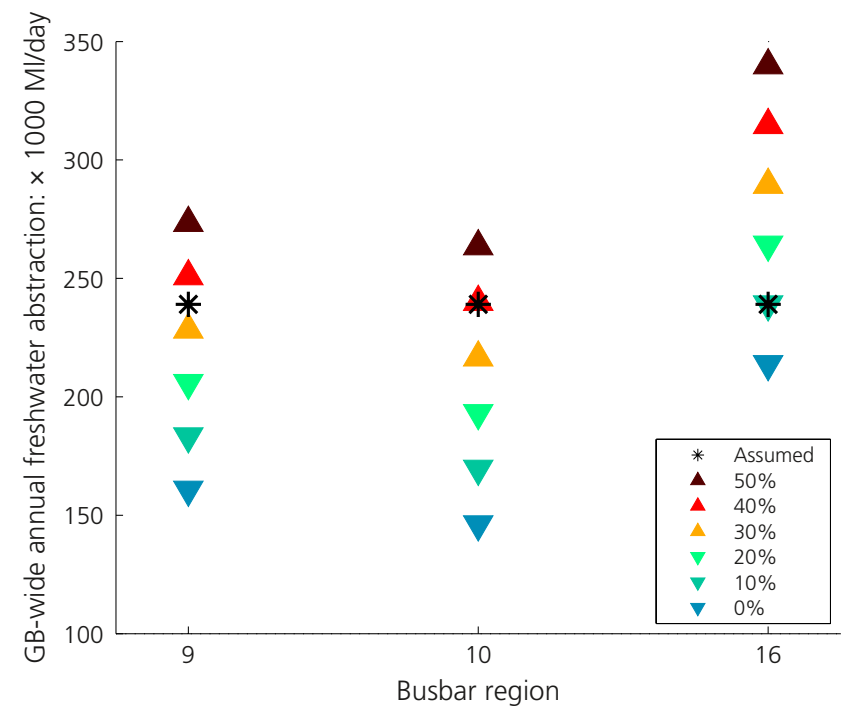

Figure 8. Sensitivity of total freshwater abstraction in EHT-CCS to changes in capacity distribution across busbar regions in 2050
These two sensitivity analyses may be compared with possible policy options. The first test is considered akin to limiting the level of capacity development on freshwater in a region in order to constrain freshwater use, hence pushing capacity development to use tidal and coastal water sources or aircooled systems. In this case, particular focus on busbars 9 and 10 would bring considerable reductions, quantified in Figure 8. The second test represents more of a regulatory regime, such as water-use efficiency targets or the mandate of specific lowwater hybrid cooling technologies, whereby water-use efficiency gradually increases. This would be effective in the EHT-CCS strategy, yet probably unnecessary in the other two strategies.

\subsection{Converging threats}

A warming climate is likely to bring reduced run-off and water availability to the UK, yet the pressure to decarbonise the electricity system may lead to greater water intensity. Delays in the

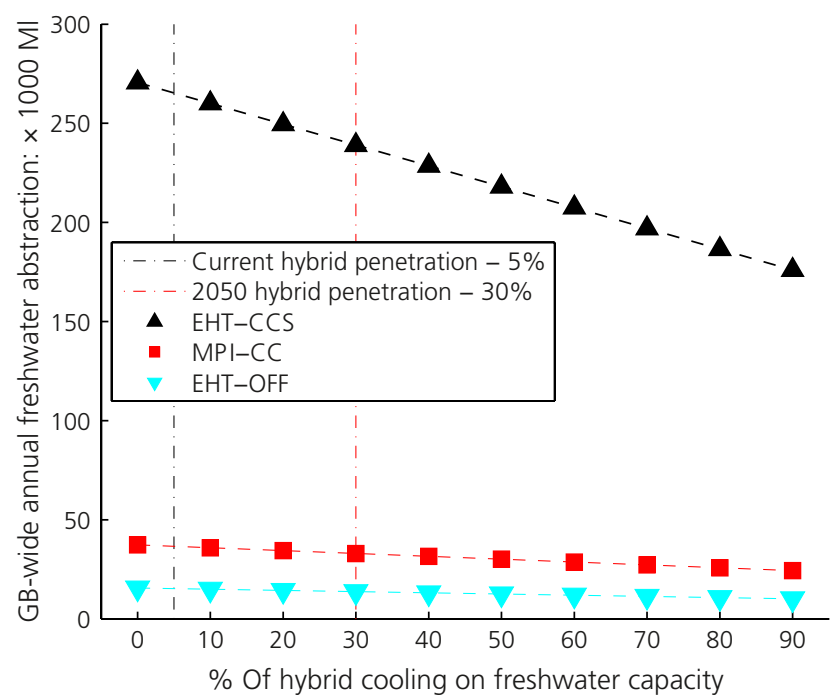

Figure 9. Sensitivity of freshwater use to the penetration of hybrid cooling on freshwater capacity, for all three strategies 
electricity market reform and the recently ascended Energy Act 2013 (2013) have resulted in stagnated capacity development in recent years. Furthermore, CCS technology is still in development. Hence, there is still the opportunity for a coordinated approach to address the issues highlighted in this paper.

Coherent policy at the interface between the energy and water sectors is essential if one has to govern successfully the high penetration of CCS capacity in a water-scarce future. Encouraged by the government's CCS roadmap (DECC, 2012a), CCS facilities will be developed in close proximity to one another to reduce infrastructure costs. Byers et al. (2014) and Naughton et al. (2012) have previously noted concern on the water impacts of 'CCS clustering', and this was embodied in this modelling work given the high capacities of CCS generation in busbars 9 and 10, in particular. Further policy attention to water-intensive CCS clusters is therefore warranted to investigate the extent of cost reductions against potential water impacts.

Meanwhile, Defra is currently investigating various options for water abstraction reform, with the aim of a more dynamic regime that will also facilitate water trading. The regulatory instruments that are implemented could have an impact on the future of UK electricity supply in determining either technology choice or location of generation capacity. China has implemented its 'Three Red Lines' policy based on economic productivity of different sectors, to drive efficiency and to increase water availability to other users (Liu et al., 2013).

The possibility for water trading also features as an option in the abstraction reform process. Water trading in Australia's Murray Darling Basin has resulted in water being reallocated to more productive uses during prolonged drought. However, it raises unexplored challenges in terms of the joint operation and regulation of interdependent water and energy markets. How water trading would operate during low flows remains a concern to the energy industry (Energy UK, 2014). There are a few, very high-volume abstractors (electricity included) and many very low-volume abstractors. Large abstractors would require many small abstractors to forgo water abstraction in order to make up deficits, unless water is available from another high-volume user, such as water companies or other, possibly less efficient, power generators.

\section{Conclusions}

Taking projections of water use by the sector, the authors have made a high-level assessment comparing demands against water resource availability on a regional basis and in a changing climate. This has enabled identification of potential conflicts between water availability and thermoelectric generation.

At the national scale, electricity strategies with high penetrations of CCS capacity will lead to high freshwater use, while strategies with more nuclear and offshore renewables minimise freshwater use. At the regional level, in strategies with high CCS, large increases in water demands may be expected in NW England and Humber/E Midlands and Yorkshire regions. The Thames and SE regions can also expect higher demands for freshwater, although it is more likely that electricity generation capacity will be forced onto tidal and coastal water sources given the considerable existing pressures on water resources.

The authors' evaluation of future water resources has estimated future cooling water availability against the expected demands in scenarios with high uptake of CCS and found that availability at very low flows $\left(Q_{\mathrm{e} 95}\right.$ and $\left.Q_{\mathrm{e} 99}\right)$ will be exceeded in regions with high demands. This is the case at both average and especially at $100 \%$ load factors. Even without the expected impacts of climate change, the authors have identified cases where there may be constraints.

Subsequently, the sensitivity analysis has indicated where cooling water demand reductions would be most beneficial. Reducing the generation capacity on freshwater in either or both NW England and Humber/E Midlands regions could bring substantial regional reductions and reduce the national water use for electricity generation by between a third and a half. Alternatively, increasing the penetration of hybrid cooling systems would bring effective water-use reductions in the EHTCCS strategy.

As a final point, the authors reiterate that the future regulatory arrangements for the energy sector and water abstraction will influence technology and location choices. Furthermore, the delayed development of CCS, imminent generation capacity renewal and the abstraction reform being considered by Defra mean there are opportunities to manage effectively this crosssectoral risk. It is essential that decision-makers take holistic and strategic views to long-term infrastructure planning to ensure both energy and water security.

\section{Acknowledgements}

The authors acknowledge funding from the Engineering and Physical Sciences Research Council grant EP/I01344X/1 to the Infrastructure Transitions Research Consortium, the respective authors' host institutions of Newcastle University, Cardiff University and University of Oxford, and two anonymous reviewers for their constructive comments on the manuscript.

\section{REFERENCES}

Bostock M (2012) Sankey Diagrams. See http://bost.ocks.org/ mike/sankey/ (accessed 27/02/2015).

Baruah PJ, Eyre N, Qadrdan M et al. (2014) Energy system impacts from heat and transport electrification. 
Proceedings of the Institution of Civil Engineers - Energy 167(3): 139-151, http://dx.doi.org/10.1680/ener.14.00008.

Byers EA, Hall JW and Amezaga JM (2014) Electricity generation and cooling water use: UK pathways to 2050 . Global Environmental Change 25: 16-30, http://dx.doi.org/ 10.1016/j.gloenvcha.2014.01.005.

CCC (Committee on Climate Change) (2010) The Fourth Carbon Budget - Reducing Emissions Through the 2020s. Committee on Climate Change, London, UK.

CEH (Centre for Ecology \& Hydrology) (2012) National River Flow Archive. Centre for Ecology and Hydrology, Wallingford, UK. See http://www.ceh.ac.uk/data/nrfa/ (accessed 27/02/2015).

Chaudry M, Jenkins N and Strbac G (2008) Multi-time period combined gas and electricity network optimisation. Electric Power Systems Research 78(7): 1265-1279, http://dx.doi. org/10.1016/j.epsr.2007.11.002.

Chaudry M, Jenkins N, Quadrdan M and Wu J (2014) Combined gas and electricity network expansion planning. Applied Energy 113: 1171-1187, http://dx.doi.org/10.1016/ j.apenergy.2013.08.071.

Christierson BV, Vidal J-P and Wade SD (2012) Using UKCP09 probabilistic climate information for UK water resource planning. Journal of Hydrology 424-425: 48-67, http://dx.doi.org/10.1016/j.jhydrol.2011.12.020.

Climate Change Act 2008 (2008) Elizabeth II. Chapter 27. Her Majesty's Stationery Office, London, UK.

Cohen SM, Macknick J, Averyt K and Meldrum J (2014) Modeling Climate-Water Impacts on Electricity Sector Capacity Expansion. National Renewable Energy Laboratory, Boulder, CO, USA. See http://www.nrel.gov/ docs/fy14osti/61435.pdf (accessed 18/06/2014).

Counsell T (2013) Sankey. https://github.com/tamc/Sankey (accessed 10/04/2015).

DECC (Department of Energy \& Climate Change) (2010) 2050 Pathways Analysis. Department of Energy \& Climate Change, London, UK.

DECC (2012a) CCS Roadmap. Department of Energy \& Climate Change, London, UK. See https://www.gov. uk/government/uploads/system/uploads/attachment_ data/file/48317/4899-the-ccs-roadmap.pdf (accessed $10 / 04 / 2015)$.

DECC (2012b) Gas Generation Strategy. Department of Energy \& Climate Change, London, UK. See https://www.gov.uk/ government/uploads/system/uploads/attachment_data/file/ 65654/7165-gas-generation-strategy.pdf (accessed 30/04/2015).

DECC (2014) Digest of United Kingdom Energy Statistics 2014. Department of Energy and Climate Change, London, UK. See https://www.gov.uk/government/uploads/system/ uploads/attachment_data/file/338768/DUKES_2014_ internet_content.pdf (accessed 10/04/2015).

Delgado A (2012) Water Footprint of Electric Power Generation: Modeling its Use and Analyzing Options for a Water-Scarce Future. Massachusetts Institute of Technology, Cambridge, MA, USA.

EA (Environment Agency) (2002) Summary of the RAM Framework. Environment Agency, Bristol, UK, R\&D Manual W6-066M Version 3.

EA (2012) Estimated Abstractions from Non-Tidal Surface Waters by Purpose and Environment Agency Region: 2000-2011. Environment Agency, Department for Environment, Food \& Rural Affairs, Bristol, UK. See https://www.gov.uk/government/uploads/system/uploads/ attachment_data/file/142124/iwtb23b-ab-tidal-E-201212_ tidal.csv (accessed 10/04/2015).

EA (2013) Environmental Flow Indicator. Environment Agency, Department for Environment, Food \& Rural Affairs, Bristol, UK. See http://webarchive. nationalarchives.gov.uk/20140328084622/http://cdn. environment-agency.gov.uk/LIT_7935_811630.pdf (accessed 21/04/2015).

Energy Act 2013 (2013) Elizabeth II. Chapter 32. Her Majesty's Stationery Office, London, UK.

Energy UK (2014) Response to Defra Consultation Making the Most of Every Drop - Reforming the Water Abstraction Management System. Energy UK, London, UK. See http://www.energy-uk.org.uk/publication.html?task=file. download\&id=2954 (accessed 10/04/2015).

Förster H and Lilliestam J (2009) Modeling thermoelectric power generation in view of climate change. Regional Environmental Change 10(4): 327-338, http://dx.doi.org/ 10.1007/s10113-009-0104-x.

Global CCS Institute (2013) The Global Status of CCS: 2013. Global CCS Institute, Melbourne, Australia. See http:// decarboni.se/sites/default/files/publications/115198/GlobalStatus-CCS-2013.pdf (accessed 13/04/2015).

Gupta HV, Kling H, Yilmaz K and Martinez GF (2009) Decomposition of the mean squared error and NSE performance criteria: implications for improving hydrological modelling. Journal of Hydrology 377(1-2): 80-91, http://dx.doi.org/10.1016/j.jhydrol.2009.08.003.

Hadian S and Madani K (2013) The water demand of energy: implications for sustainable energy policy development. Sustainability 5(11): 4674 4687, http://dx.doi.org/10.3390/ su5114674.

Hall JW, Henriques J, Hickford A et al. (2012) A Fast Track Analysis of Strategies for Infrastructure Provision in Great Britain. Environmental Change Institute, University of Oxford, Oxford, UK.

Hall JW, Henriques JJ, Hickford AJ and Nicholls RJ (2013) Systems-of-systems analysis of national infrastructure. Proceedings of the Institution of Civil Engineers Engineering Sustainability 166(5): 249-257, http://dx.doi. org/10.1680/ensu.12.00028.

Hall JW, Henriques JJ, Hickford AJ et al. (2014) Assessing the long-term performance of cross-sectoral strategies for 
national infrastructure. Journal of Infrastructure Systems 20(3): 04014014, http://dx.doi.org/10.1061/(ASCE)IS.1943555X.0000196.

Hall JW, Nicholls RJ, Tran M and Hickford A (2015) The Future of National Infrastructure: A System-of-Systems Approach. Cambridge University Press, Cambridge, UK, in press. HMG (Her Majesty's Government) (2011) The Carbon Plan: Delivering Our Low Carbon Future. Department of Energy \& Climate Change, London, UK.

IEAGHG (International Energy Agency Greenhouse Gas R\&D Programme) (2011) Evaluation and Analysis of Water Usage of Power Plants with $\mathrm{CO}_{2}$ Capture. International Energy Agency, Cheltenham, UK.

Jones PD, Kilsby CG, Harpham C, Glenis V and Burton A (2009) UK Climate Projections Science Report: Projections of Future Daily Climate for the UK from the Weather Generator. University of Newcastle, Newcastle upon Tyne, UK.

Kilsby CG, Jones PD, Burton A et al. (2007) A daily weather generator for use in climate change studies. Environmental Modelling \& Software 22(12): 1705-1719, http://dx.doi.org/ 10.1016/j.envsoft.2007.02.005.

Koch H and Vögele S (2009) Dynamic modelling of water demand, water availability and adaptation strategies for power plants to global change. Ecological Economics 68(7): 2031-2039, http://dx.doi.org/10.1016/j.ecolecon.2009.02.015.

Koch $\mathrm{H}$ and Vögele S (2013) Hydro-climatic conditions and thermoelectric electricity generation - part I: development of models. Energy 63: 42-51, http://dx.doi.org/10.1016/ j.energy.2013.10.018.

Koch H, Vögele S, Kaltofen M, Grossmann M and Grünewald U (2014) Security of water supply and electricity production: aspects of integrated management. Water Resources Management 28(6): 1767-1780, http://dx.doi.org/10.1007/ s11269-014-0589-z.

Liu J, Zang C, Tian S et al. (2013) Water conservancy projects in China: achievements, challenges and way forward. Global Environmental Change 23(3): 633-643, http://dx.doi.org/10.1016/j.gloenvcha.2013.02.002.

Lopez A, Fung F, New M et al. (2009) From climate model ensembles to climate change impacts and adaptation: a case study of water resource management in the southwest of England. Water Resources Research 45(8), http://dx.doi. org/10.1029/2008WR007499.

Macknick J, Newmark R, Heath G et al. (2011) A Review of Operational Water Consumption and Withdrawal Factors for Electricity Generating Technologies. National Renewable Energy Laboratory, Golden, CO, USA.

Macknick J, Newmark R, Heath G et al. (2012a) Operational water consumption and withdrawal factors for electricity generating technologies: a review of existing literature. Environmental Research Letters 7(4): 045802, http://dx.doi. org/10.1088/1748-9326/7/4/045802.
Macknick J, Sattler S, Averyt K, Klemmer S and Rogers J (2012b) The water implications of generating electricity: water use across the United States based on different electricity pathways through 2050. Environmental Research Letters 7(4): 045803, http://dx.doi.org/10.1088/1748-9326/7/4/ 045803.

Murphy JM, Sexton DMH, Jenkins GJ et al. (2009) UK Climate Projections Science Report: Climate Change Projections. Met Office Hadley Centre, Exeter, UK.

Nakicenovic N and Swart R (2000) Emissions Scenarios. Cambridge University Press, Cambridge, UK.

Naughton M, Darton RC and Fung F (2012) Could climate change limit water availability for coal-fired electricity generation with carbon capture and storage? A UK case study. Energy and Environment 23(2 and 3): 265-282.

New M, Lopez A, Dessai S and Wilby R (2007) Challenges in using probabilistic climate change information for impact assessments: an example from the water sector. Philosophical Transactions. Series A, Mathematical, Physical, and Engineering Sciences 365(1857): 2117-2131, http://dx.doi. org/10.1098/rsta.2007.2080.

NG (National Grid) (2014) UK Future Energy Scenarios. National Grid, Warwick, UK. See http://www2. nationalgrid.com/uk/industry-information/future-of-energy/ future-energy-scenarios/ (accessed 27/02/2015).

Pan L, Liu P, Ma L and Li Z (2012) A supply chain based assessment of water issues in the coal industry in China. Energy Policy 48: 93-102, http://dx.doi.org/10.1016/j.enpol. 2012.03.063.

PB (Parsons Brinckerhoff) (2012) Water Demand for Carbon Capture and Storage (CCS). Environment Agency, Department for Environment, Food and Rural Affairs, Bristol, UK.

Perry M and Hollis D (2005a) The development of a new set of long-term climate averages for the UK. International Journal of Climatology 25(8): 1023-1039, http://dx.doi.org/ 10.1002/joc. 1160.

Perry M and Hollis D (2005b) The generation of monthly gridded datasets for a range of climatic variables over the UK. International Journal of Climatology 25(8): 1041-1054, http://dx.doi.org/10.1002/joc.1161.

Prudhomme C, Crooks S, Jackson C et al. (2012) Future Flows and Groundwater Levels. Centre for Ecology and Hydrology, Wallingford, UK, final technical report. See http://www.ceh.ac.uk/sci_programmes/water/future $\%$ 20flows/documents/futureflowsandgroundwaterlevels_pn9_ finalreport_finaloct2012.pdf (accessed 21/04/2015).

Prudhomme C, Haxton T, Crooks S et al. (2013) Future flows hydrology: an ensemble of daily river flow and monthly groundwater levels for use for climate change impact assessment across Great Britain. Earth System Science Data 5(1): 101-107, http://dx.doi.org/10.5194/essd-5-1012013. 
Rance J, Wade SD, Hurford AP, Bottius E and Reynard NS (2012) Climate Change Risk Assessment for the Water Sector. Department for Environment, Food and Rural Affairs, London, UK.

Scanlon BR, Reedy R, Duncan I, Mullican WF and Young M (2013) Controls on water use for thermoelectric generation: case study Texas, US. Environmental Science \& Technology 47(19): 11326-11334, http://dx.doi.org/ 10.1021/es4029183.

Spanger-Siegfried E (2013) If You Can't Take the Heat: How Summer 2012 Strained U.S. Power Plants. Union of Concerned Scientists, Cambridge, MA, USA. See http://blog.ucsusa.org/if-you-cant-take-the-heat-howsummer-2012-strained-u-s-power-plants (accessed 13/05/ 2014).

Stillwell AS and Webber ME (2013) Evaluation of power generation operations in response to changes in surface water reservoir storage. Environmental Research Letters 8(2): 025014, http://dx.doi.org/10.1088/1748-9326/8/2/ 025014

Stillwell AS, Clayton ME and Webber ME (2011) Technical analysis of a river basin-based model of advanced power plant cooling technologies for mitigating water management challenges. Environmental Research Letters 6(3): 034015, http://dx.doi.org/10.1088/1748-9326/6/3/ 034015 .

TPI (The Planning Inspectorate) (2012) National Infrastructure Planning: Planning Inspectorate Role. The Planning Inspectorate, Bristol, UK. See http://infrastructure. planningportal.gov.uk/application-process/planninginspectorate-role/ (accessed 13/04/2015).

Tran M, Hall J, Hickford A et al. (2014) National Infrastructure Assessment: Analysis of Options for Infrastructure Provision in Great Britain, Interim Results. Environmental Change Institute, University of Oxford, Oxford, UK.

Tzimas E (2011) Sustainable or Not? Impacts and Uncertainties of Low-Carbon Energy Technologies on Water. European Commission Joint Research Centre Institute for Energy and Transport, Ispra, Italy. See https://ec.europa.eu/jrc/ sites/default/files/jrc_aaas2011_energy_water_tzimas.pdf (accessed 13/04/2015).

UCS (Union of Concerned Scientists) (2011) The Energy-Water Collision: Power and Water at Risk. Union of Concerned Scientists, Cambridge, MA, USA. See http://www.ucsusa. org/sites/default/files/legacy/assets/documents/clean_energy/ ew3/power-and-water-at-risk-with-endnotes.pdf (accessed 13/04/2015).

UCS (2012) The Energy Water Collision. Union of Concerned Scientists, Cambridge, MA, USA. See http://www.ucsusa. org/assets/images/ce/Infographic-The-Energy-WaterCollision_All-Facts_Full-Size.jpg (accessed 26/05/2014).

Wall M (1996) A genetic algorithm for resource-constrained scheduling. $\mathrm{PhD}$ thesis, Massachusetts Institute of
Technology, Cambridge, MA, USA. See http://lancet.mit. edu/ mwall/phd/thesis/thesis.pdf (accessed 13/06/2014).

Water Resources Act 1991 (1991) Elizabeth II. Chapter 57. Her Majesty's Stationery Office, London, UK, part II, chapter III.

Whitehead PG, Crossman J, Balana BB et al. (2013) A costeffectiveness analysis of water security and water quality: impacts of climate and land-use change on the River Thames system. Philosophical Transactions. Series A, Mathematical, Physical, and Engineering Sciences 371(2002): 20120413, http://dx.doi.org/10.1098/rsta. 2012.0413.

Wilby RL, Orr HG, Hedger M, Forrow D and Blackmore M (2006) Risks posed by climate change to the delivery of water framework directive objectives in the UK. Environment International 32(8): 1043-1055, http://dx.doi.org/10.1016/ j.envint.2006.06.017.

Zhai $\mathrm{H}$ and Rubin ES (2010) Performance and cost of wet and dry cooling systems for pulverized coal power plants with and without carbon capture and storage. Energy Policy 38(10): 5653-5660, http://dx.doi.org/10.1016/j.enpol.2010. 05.013.

Zhai H, Rubin ES and Versteeg PL (2011) Water use at pulverized coal power plants with postcombustion carbon capture and storage. Environmental Science \& Technology 45(6): 2479-2485, http://dx.doi.org/10.1021/es1034443.

\section{WHAT DO YOU THINK?}

To discuss this paper, please email up to 500 words to the editor at journals@ice.org.uk. Your contribution will be forwarded to the author(s) for a reply and, if considered appropriate by the editorial panel, will be published as discussion in a future issue of the journal.

Proceedings journals rely entirely on contributions sent in by civil engineering professionals, academics and students. Papers should be 2000-5000 words long (briefing papers should be 1000-2000 words long), with adequate illustrations and references. You can submit your paper online via www.icevirtuallibrary.com/content/journals, where you will also find detailed author guidelines. 